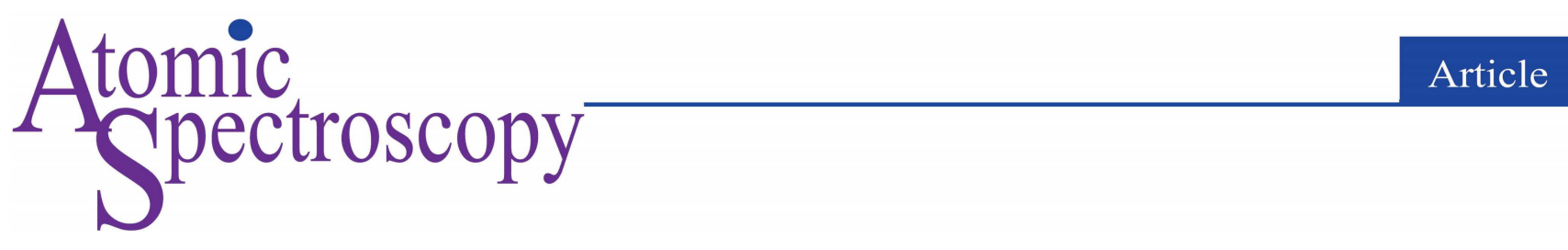

\title{
Determination of Elemental Impurities in Iron-nickel-based Superalloys by Glow Discharge Mass Spectrometry
}

\author{
F. F. Hu, ${ }^{a}$ C. H. Wang, ${ }^{a}, *$ J. D. Li, ${ }^{b}$ P. Y. Liu, ${ }^{b}$ H. Liu, ${ }^{a}$ and L. Zhang ${ }^{a}$ \\ a Guobiao (Beijing) Testing \& Certification Co., Ltd., Beijing 101407, P.R. China \\ b China United Test \& Certification Co., Ltd., Beijing 101407, P.R. China
}

Received: November 27, 2020; Revised: December 20, 2020; Accepted: December 20, 2020; Available online: December 25, 2020.

DOI: $10.46770 / A S .2020 .215$

\begin{abstract}
A method for the determination of impurities in iron-nickel-based superalloys by high-resolution glow discharge mass spectrometry is described. The optimum discharge conditions were investigated to obtain stable discharge and good sensitivity. The interference was separated in high resolution mode of the instrument. The calibration relative sensitivity factors (RSF) for 12 elements were obtained with the matrix-matched certified reference material, IARM Ni909-18. The reference material was analyzed by using the calibration RSFs. The relative error of the measured value was within $16.4 \%$ compared with the certified value, and the relative standard deviation (RSD) was less than 7.0\%. The 12 elements in the iron-nickel-based superalloy were determined using the calibration RSFs (quantitative analysis) and the standard RSFs (semi-quantitative analysis) in the instrument, including C, $\mathrm{N}, \mathrm{O}$ and $\mathrm{S}$. The results of the verification methods, such as inductively coupled plasma optical emission spectrometry (ICP-OES), inductively coupled plasma mass spectrometry (ICP-MS), high frequency combustion infrared absorption and inert gas pulse infrared thermal conductivity, were closer to quantitative analysis results. The elements without certified values in the reference material were determined by using the standard RSFs. There was no significant difference between the results of GDMS and the verification by ICP-MS. The validation revealed that the proposed analytical approach achieves reliable results for the rapid determination of several impurities, such as metals as well as non-metals, even the gas elements $\mathrm{C}, \mathrm{N}, \mathrm{O}$ and $\mathrm{S}$.

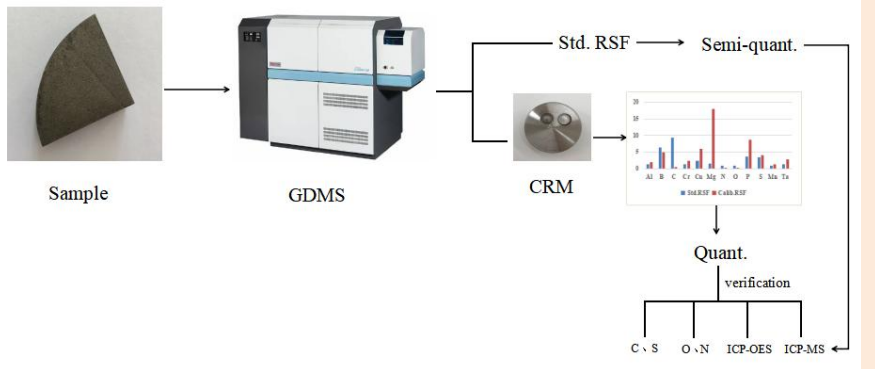

\section{INTRODUCTION}

A superalloy is mainly an iron-, nickel- or cobalt-based metallic material, which works under the conditions of certain stress factors and at high temperatures of above $600{ }^{\circ} \mathrm{C} .1^{1}$ Because of its characterization of having high-temperature resistance, oxidation resistance and corrosion resistance, superalloys are widely used in the aerospace and energy industries..$^{2-3}$ With the increasing demand for high-performance aeroengine and turbine designs, the performance of superalloys is also expected to be higher. Elements and their concentrations in superalloys influence their application and performance. ${ }^{4}$ Therefore, the accurate determination of trace elements in superalloys is very important. However, the components of superalloys are complicated and, therefore, requires their accurate determination.
The American Society for Testing and Materials (ASTM), one of the international authoritative standard systems, has developed testing methods for different elements in superalloys. ${ }^{5-8}$ These methods cover the major, minor and trace elements in nickel-based superalloys. However, their deficiency is that it only covers few elements and slightly higher detection limits. The International Organization for Standardization (ISO) methods for the chemical composition of superalloys are mostly for single elements.9-11 Obviously, the detection efficiency is low. Most of the Chinese standard analysis methods for superalloy compositions are chemical analysis methods, but only a few instrumental methods are developed. ${ }^{12-15}$ The pretreatment of classical chemical methods is complex, and the detection efficiency is low. Moreover, some of the elemental detection methods are based on the analysis of steel. ${ }^{14-15}$ 
The reported methods for the determination of trace elements in superalloys include flame atomic absorption spectrometry (FAAS) ${ }^{16}$ inductively coupled plasma optical emission spectrometry (ICP-OES), ${ }^{17}$ inductively coupled plasma mass spectrometry (ICP-MS), ${ }^{18-20}$ glow discharge mass spectrometry (GDMS), ${ }^{21-23}$ etc. The detection efficiency of FAAS is low because of single element determination and the detection limit of ICP-OES is slightly higher for trace elements. The mass spectrometric interference in superalloys with a relatively simple matrix is slight and therefore, the detection limit of ICP-MS can basically meet the detection requirements. However, for superalloys with more complex matrices, ICP-MS cannot meet the demand.

Glow discharge mass spectrometry (GDMS) is a method for the direct analysis of solid samples. The sample serves as the cathode for a glow discharge in inert gas, usually Ar. Atoms are released from the sample surface by cathode sputtering and then ionized in the negative glow region by the Penning ionization and electron impact ionization process. Since the atomization and ionization of a sample in the GD source are carried out in two different regions, namely the cathode dark area near the surface of the sample and the negative glow region near the anode, GDMS has the advantage of low matrix effects. Moreover, it is fast, offers high sensitivity, high resolution, and can be used for qualitative or quantitative analysis of almost all elements in the periodic table. GDMS is considered to be the most effective method for the direct determination of trace and ultra-trace elements in solid conductive materials ${ }^{24}$ and is widely used in the analysis of metals, alloys, semiconductors, etc. ${ }^{25-32}$

In an analysis, the interference affects the accuracy of the results, so mass spectrometric interferences should be fully considered in GDMS analysis, ${ }^{21-22,27,33-35}$ especially for a complex matrix. The main interferences in GDMS analysis are heterotopic interference, polyatomic ion interference and multi-charge ion interference. The interferences can be reduced or eliminated by selecting a noninterference isotope, establishing a mathematical correction equation, adding a collision reaction cell system, using a highresolution instrument, changing the discharge gas, improving the purity of the discharge gas, cooling the ion source, and so on.

The relative sensitivity factor (RSF) is actually a correction factor, which relates the measured relative ion currents to the actual relative concentrations in the analyzed sample. Because of the low matrix effects as mentioned above, GDMS analysis can be considered being almost independent of matrix. When no suitable certified reference material can be found, the RSF obtained from one matrix reference material can be used to analyze another matrix sample. ${ }^{25-27}$ In recent years, scholars have done more research on RSF. ${ }^{36-37}$ However, the experimental results show that some elements in some matrices cannot provide satisfactory results after being corrected by RSF obtained from different matrix reference materials. ${ }^{28-29}$
Table 1. Elements and Concentrations in Certified Reference Material (IARM Ni909-18)

\begin{tabular}{lccccc}
\hline Element & $\begin{array}{c}\text { Content } \\
\boldsymbol{w} / \boldsymbol{\%}\end{array}$ & $\begin{array}{c}\text { Uncertainty } \\
\boldsymbol{w} / \boldsymbol{\%}\end{array}$ & Element & $\begin{array}{c}\text { Content } \\
\boldsymbol{w} / \%\end{array}$ & $\begin{array}{c}\text { Uncertainty } \\
\boldsymbol{w} / \boldsymbol{\%}\end{array}$ \\
\hline $\mathbf{A l}$ & 0.009 & 0.002 & $\mathbf{N}$ & 0.0026 & 0.0003 \\
$\mathbf{B}$ & 0.0013 & 0.0005 & $\mathbf{N b}$ & 4.6 & 0.1 \\
$\mathbf{C}$ & 0.006 & 0.001 & $\mathbf{N i}$ & 37.7 & 0.2 \\
$\mathbf{C o}$ & 13.1 & 0.1 & $\mathbf{O}$ & 0.004 & 0.001 \\
$\mathbf{C r}$ & 0.01 & 0.004 & $\mathbf{P}$ & 0.002 & 0.001 \\
$\mathbf{C u}$ & 0.007 & 0.004 & $\mathbf{S}$ & 0.0018 & 0.0004 \\
$\mathbf{F e}$ & 42.4 & 0.3 & $\mathbf{S i}$ & 0.42 & 0.01 \\
$\mathbf{M g}$ & 0.00012 & 0.00007 & $\mathbf{T a}$ & 0.006 & 0.003 \\
$\mathbf{M n}$ & 0.03 & 0.003 & $\mathbf{T i}$ & 1.62 & 0.03 \\
\hline
\end{tabular}

$\mathrm{X} . \mathrm{Yu}^{21-22}$ and $\mathrm{K} \cdot \mathrm{Su}^{23}$ have done some work on the determination of trace elements in superalloys by glow discharge mass spectrometry. They focused on mass spectrometric interference and depth analysis in superalloy, but did not discuss RSF and quantitative analysis. In this study, the experimental conditions were optimized. The standard RSFs of some elements in the instrument were corrected by using a matrix-matched ironnickel-based superalloy certified reference material (IARM Ni909-18), and the trace elements in the sample were analyzed by high resolution glow discharge mass spectrometry, including $\mathrm{C}, \mathrm{O}$, $\mathrm{N}$, and $\mathrm{S}$. The elements and concentrations in the certified reference material (IARM Ni909-18) are listed in Table 1. For other elements without definite value in the certified reference material, semi-quantitative results were obtained by using the standard RSF in the instrument. The methods of ICP-OES, ICPMS, high frequency combustion infrared absorption and inert gas pulse infrared thermal conductivity were used to verify the results obtained by GDMS.

\section{EXPERIMENTAL}

Analysis by GDMS. A high-resolution glow discharge mass spectrometer (Thermo Fisher, USA, Model: Element GD) was used for this study, which was equipped with a Grimm-type fast flow glow discharge ion source. The purity (volume fraction) of the argon discharge gas is more than $99.9999 \%$. The glow discharge ion source adopts semiconductor temperature control, which could be cooled or heated. The samples should have a smooth surface and were loaded onto a sample holder with an inner diameter of $18.8 \mathrm{~mm}$. The sample was sputtered, atomized, ionized, and then focused before entering the magnet. After the mass separation by the ions' momentum in the magnetic field, the electrostatic analyzer served for an energy separation to achieve high resolution capabilities required for the separation of polyatomic interference species from the analyte signals. Finally, the ions on their respective mass were counted by the detection system. The mass analyzer separated the ions according to their mass and charge ratio. The Element GD has three detector modes, namely the counting and the analog detectors obtained by a secondary electron multiplier (SEM), and the Faraday detector. The resolution slit allowed three stage-fixed resolutions, i.e., low 
( $\mathrm{R}=300)$, medium $(\mathrm{R}=4000)$ and high $(\mathrm{R}=10000)$ resolution. Instrument control and data acquisition were handled by Element GD software. The peak jump mode was chosen in data acquisition. A brass block was used for mass calibration of the instrument over the entire mass range. The detectors' calibration was done on a day-to-day basis by a tantalum block. The measurements were carried out with a mass step of $0.01 \mathrm{amu}$ and 120 number of data points per peak. The standard RSF (also called typical RSF), derived from a variety of metals and alloys, is built into the instrument software.

Sample preparation and measurement details. First, the grease on the surface of the iron-nickel-based superalloy was cleaned with ethanol, then cleaned with deionized water. Dilute aqua regia was used to corrode the surface of the superalloy sample to remove possible contamination, then cleaned with deionized water. The sample was then dried with nitrogen and subsequently loaded into the GDMS system using a flat sample holder. The discharge parameters were optimized in constant current mode to obtain enough and stable counts per second for ${ }^{56} \mathrm{Fe}^{+}$and ${ }^{58} \mathrm{Ni}^{+}$. The optimized discharge conditions of the GDMS for the iron and nickel matrix signal are listed in Table 2. The superalloy was pre-sputtered for 10 minutes to remove the trace residues on the surface using a discharge current of $30 \mathrm{~mA}$ and a discharge gas flow rate of $430 \mathrm{~mL} / \mathrm{min}$. The main elements, such as $\mathrm{Fe}$ and $\mathrm{Ni}$, were detected by Faraday detector, the impurity elements were determined by SEM detector. Four repetitive measurements were recorded for all isotopes.

Determination of impurities by ICP-OES. A $0.10 \mathrm{~g}$ amount (accurate to $0.0001 \mathrm{~g}$ ) of iron-nickel-based superalloy sample was weighed into a $250 \mathrm{~mL}$ polytetrafluoroethylene beaker, then $3 \mathrm{~mL}$ hydrochloric acid, $1 \mathrm{~mL}$ nitric acid and $1 \mathrm{~mL}$ hydrofluoric acid, heated to $220^{\circ} \mathrm{C}$ on an electric hot plate to dissolve the sample completely, then the beaker was removed and left standing to cool. The contents were transferred into a $100 \mathrm{~mL}$ volumetric flask, then diluted to the mark with deionized water, and mixed. The sample solution was nebulized into the inductively coupled plasma optical emission spectrometer (Agilent $725 \mathrm{ES}$, USA) to determine Mn by the matrix matching method. The pure metals [Fe, Ni Co, Ti, and $\mathrm{Nb}$, purity $\geqslant 99.99 \%$ (mass fraction)] were added with the same mass as the main component of the superalloy, dissolved, and the $\mathrm{Mn}$ standard stock solution $(1 \mathrm{mg} / \mathrm{mL})$ added after appropriate dilution (National Center for Analysis and Testing of Non-ferrous Metals and Electronic Materials, P.R. China).

Determination of impurities by ICP-MS. The iron-nickel-based superalloy sample $(0.1 \mathrm{~g}$, accurate to $0.0001 \mathrm{~g})$ was dissolved into a $250 \mathrm{~mL}$ polytetrafluoroethylene beaker by adding $3 \mathrm{~mL}$ hydrochloric acid, $1 \mathrm{~mL}$ nitric acid and $1 \mathrm{~mL}$ hydrofluoric acid, then heating. The solution was transferred to a $100 \mathrm{~mL}$ volumetric flask, Cs internal standard solution was added, then diluted to the mark with deionized water, and mixed. The sample solution was nebulized into the inductively coupled plasma mass spectrometer
Table 2. The Optimized Parameters for GDMS

\begin{tabular}{ll}
\hline Parameter & Value \\
\hline Discharge voltage $(\mathbf{V})$ & 1200 \\
Discharge current $(\mathbf{m A})$ & 30 \\
Discharge gas flow rate $(\mathbf{m L} / \mathbf{m i n})$ & 430 \\
Peltier $\left({ }^{\circ} \mathbf{C}\right)$ & 15 \\
Focus $(\mathbf{V})$ & -1026 \\
X-Deflection $(\mathbf{V})$ & 1.93 \\
Y-Deflection $(\mathbf{V})$ & 0.23 \\
Mass resolution & $4000,10,000$ \\
\hline
\end{tabular}

(Agilent 7700, USA) to determine $\mathrm{Li}, \mathrm{Be}, \mathrm{B}, \mathrm{Na}, \mathrm{Mg}, \mathrm{Al}, \mathrm{P}, \mathrm{K}, \mathrm{Ca}$, $\mathrm{Sc}, \mathrm{V}, \mathrm{Cr}, \mathrm{Cu}, \mathrm{Zn}, \mathrm{Ga}, \mathrm{Ge}, \mathrm{As}, \mathrm{Se}, \mathrm{Rb}, \mathrm{Sr}, \mathrm{Y}, \mathrm{Zr}, \mathrm{Mo}, \mathrm{Ru}, \mathrm{Rh}, \mathrm{Pd}$, Ag, Cd, In, Sn, Sb, Te, Ba, La, Ce, Pr, Nd, Sm, Eu, Gd, Tb, Dy, $\mathrm{Ho}, \mathrm{Er}, \mathrm{Tm}, \mathrm{Yb}, \mathrm{Lu}, \mathrm{Hf}, \mathrm{Ta}, \mathrm{W}, \mathrm{Re}, \mathrm{Os}, \mathrm{Ir}, \mathrm{Pt}, \mathrm{Au}, \mathrm{Hg}, \mathrm{Tl}, \mathrm{Pb}$ and Bi. These elements were determined by external calibration using standard solutions $(1 \mathrm{mg} / \mathrm{mL}$, National Center for Analysis and Testing of Non-ferrous Metals and Electronic Materials, P.R. China).

Determination of $\mathrm{C}$ and $\mathrm{S}$ by high frequency combustion infrared absorption method. The concentrations of $\mathrm{C}$ and $\mathrm{S}$ were measured using a high frequency infrared carbon and sulfur analyzer (LECO CS-844, USA). The flow velocity of oxygen [purity $\geqslant 99.99 \%$ (volume fraction)] was $3 \mathrm{~L} / \mathrm{min}$. The power of the high frequency furnace was $2.2 \mathrm{~kW}$, and the frequency was 18 MHz. The purge time of the high frequency infrared carbon sulfur analyzer was $10 \sim 15 \mathrm{~s}$, the delay time $20 \mathrm{~s}$, the analysis time $40 \sim 50 \mathrm{~s}$, and the comparator level $1 \sim 3$. An amount of $(0.500 \pm$ $0.005) \mathrm{g}$ iron-nickel-based superalloy sample was weighed into the crucible, and $0.70 \mathrm{~g}$ pure iron and $1.50 \mathrm{~g}$ tungsten tin flux were added to determine the $\mathrm{C}$ and $\mathrm{S}$ concentrations.

Determination of $O$ and $N$ by inert gas pulse infrared thermal conductivity method. The content of $\mathrm{O}$ and $\mathrm{N}$ was measured by using an oxygen and nitrogen analyzer (LECO ONH836, USA). The purity of helium, the carrier gas, was more than $99.99 \%$ (mass fraction). The power of the oxygen and nitrogen analyzer was set at $5.0 \mathrm{~kW}$. An amount of $0.500 \mathrm{~g}$ ironnickel-based superalloy sample was accurately weighed and put into the nickel basket for analysis.

\section{RESULTS AND DISCUSSION}

Isotope selection and mass spectrometric interference. The isotope selection of elements to be measured was based on the principle of high abundance and less interference. In GDMS analysis, the mass spectrum interference mainly came from the discharge gas and the matrix elements. For the elements that may interfered, the isotopes without interference were selected or determined in the appropriate resolution mode. The medium resolution of the Element GD was 4000 and the high resolution 10,000 , which could separate most of the interferences. The elements to be measured, the mass, interference ions, the resolutions required and resolution mode are listed in Table 3. For 
Table 3. Isotope, Mass Interference and Resolution

\begin{tabular}{|c|c|c|c|c|}
\hline Element & Mass & Interference & $\begin{array}{l}\text { Resolution } \\
\text { required }\end{array}$ & $\begin{array}{l}\text { Medium or } \\
\text { high resolution }\end{array}$ \\
\hline $\mathbf{K}$ & 39 & ${ }^{38} \mathrm{ArH}^{+}$ & 5689 & High resolution \\
\hline Ge & 72 & ${ }^{56} \mathrm{Fe}^{16} \mathrm{O}^{+}$ & 9257 & High resolution \\
\hline As & 75 & $\begin{array}{l}{ }^{57} \mathrm{Fe}^{18} \mathrm{O}^{+} \\
{ }^{58} \mathrm{Ni}^{17} \mathrm{O}^{+}\end{array}$ & 5781,5817 & High resolution \\
\hline $\mathrm{Br}$ & 79 & ${ }^{40} \mathrm{Ar}^{38} \mathrm{ArH}^{+}$ & 5406 & High resolution \\
\hline Se & 82 & $\begin{array}{c}{ }^{64} \mathrm{Ni}^{18} \mathrm{O}^{+} \\
{ }^{40} \mathrm{Ar}^{40} \mathrm{ArHH}^{+}\end{array}$ & 7862,3455 & High resolution \\
\hline Mo & 100 & ${ }^{60} \mathrm{Ni}^{40} \mathrm{O}^{+}$ & 6985 & High resolution \\
\hline Ru & 101 & ${ }^{61} \mathrm{Ni}^{40} \mathrm{O}^{+}$ & 8310 & High resolution \\
\hline Cs & 133 & ${ }^{93} \mathrm{Nb}^{40} \mathrm{Ar}^{+}$ & 3623 & $\begin{array}{l}\text { Medium } \\
\text { resolution }\end{array}$ \\
\hline
\end{tabular}

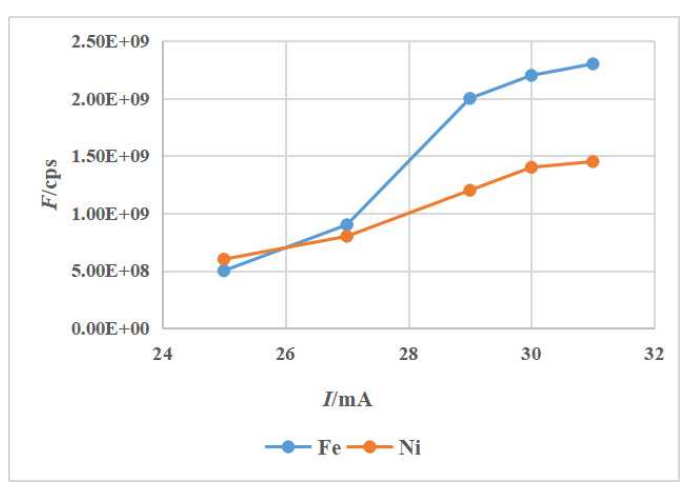

Fig. 1 Effect of discharge current on Fe and Ni signal intensity.

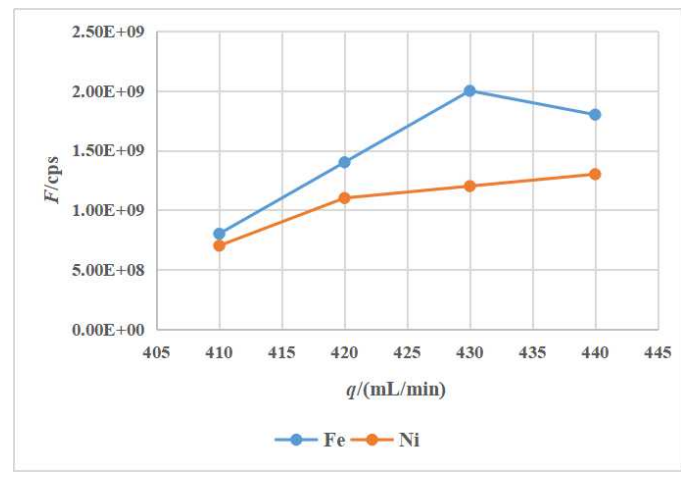

Fig. 2 Effect of argon flow rate on Fe and Ni signal intensity.

Table 4. Comparison of the contnt of $\mathrm{C}, \mathrm{N}, \mathrm{O}$, and $\mathrm{S}$ in Background, Reference Material and Superalloy Sample

\begin{tabular}{llll}
\hline Element & $\begin{array}{l}\text { Backgroud } \\
\boldsymbol{w} /(\boldsymbol{\mu g} / \mathbf{g})\end{array}$ & $\begin{array}{l}\text { Reference } \\
\boldsymbol{w} /(\boldsymbol{\mu g} / \mathbf{g})\end{array}$ & $\begin{array}{l}\text { Sample } \\
\boldsymbol{w} /(\boldsymbol{\mu g} / \mathbf{g})\end{array}$ \\
\hline $\mathbf{C}$ & 25 & 1254 & 3096 \\
$\mathbf{N}$ & 30 & 1003 & 433 \\
$\mathbf{O}$ & 100 & 1963 & 2116 \\
$\mathbf{S}$ & 0.1 & 20.3 & 7.1 \\
\hline
\end{tabular}

the elements without interference, the most abundant isotopes were selected for determination.

Optimization of discharge conditions. Discharge current, discharge voltage and discharge gas flow rate are the three main discharge parameters in GDMS analysis. One is fixed and the other two are linked. ${ }^{38}$ In this study, the maximum discharge voltage was set at $1200 \mathrm{~V}$, and the discharge current and the argon flow rate were adjusted to obtain stable discharge and enough sensitivity.

The argon flow rate was set at $410 \mathrm{~mL} / \mathrm{min}$. The signal intensities of $\mathrm{Fe}$ and $\mathrm{Ni}$ were investigated with a discharge current of $25 \mathrm{~mA}, 27 \mathrm{~mA}, 29 \mathrm{~mA}, 30 \mathrm{~mA}$ and $31 \mathrm{~mA}$. With an increase in discharge current, the atom sputtering rate from the sample increased, along with the signal intensity. The results are shown in Fig. 1. When the current was increased to $30 \mathrm{~mA}$, the increasing trend of the signal intensity decreased. Moreover, the discharge time was shortened because the sample deposition caused a short circuit. Therefore, the optimum discharge current for superalloy was set at $30 \mathrm{~mA}$.

The discharge current was set at $30 \mathrm{~mA}$. The signal intensities of $\mathrm{Fe}$ and $\mathrm{Ni}$ were investigated when the argon flow rate was 410 $\mathrm{mL} / \mathrm{min}, 420 \mathrm{~mL} / \mathrm{min}, 430 \mathrm{~mL} / \mathrm{min}$ and $440 \mathrm{~mL} / \mathrm{min}$. The argon flow rate determined the number of argon molecules involved in the collision and the ionization per unit time. When the discharge current was fixed, the argon flow rate increased and the discharge voltage decreased, which means that the sputtering rate decreased. The more argon molecules in unit time, the higher the ionization efficiency. When the ionization efficiency was greater than the sputtering rate, the signal strength increased. When the ionization efficiency was lower than the sputtering rate, the signal strength decreased. The results are shown in Fig. 2. When the argon flow rate reached $430 \mathrm{~mL} / \mathrm{min}$, the signal intensity of Fe decreased. Therefore, the optimum argon flow rate for the iron-nickel-based superalloy was at $430 \mathrm{~mL} / \mathrm{min}$. The optimized discharge conditions of the GDMS are listed in Table 2.

Quantitative analysis of GDMS. In order to obtain quantitative results, a concentration dependence of element-specific and matrix-specific sensitivity factors (named relative sensitivity factors, RSFs) has to be known. The element concentration in the matrix can be expressed as:

$$
\frac{C_{\mathrm{X}}}{C_{\mathrm{M}}}=R S F_{(\mathrm{X} / \mathrm{M})} \times \frac{I_{\mathrm{X}} / A_{\mathrm{X}}}{I_{\mathrm{M}} / A_{\mathrm{M}}}
$$

where $C_{\mathrm{X}}$ and $C_{\mathrm{M}}$ represent the concentration of the analyte and the matrix; $R S F_{(\mathrm{X} / \mathrm{M})}$ is the relative sensitivity of element $\mathrm{X}$ in the matrix; $I \mathrm{X}$ and $I_{\mathrm{M}}$ are the ion beam signals of the element $\mathrm{X}$ and the matrix, respectively; and $A_{\mathrm{X}}$ and $A_{\mathrm{M}}$ are the isotope abundances of element $\mathrm{X}$ and the matrix, respectively. The concentrations of $\mathrm{C}$, $\mathrm{N}, \mathrm{O}$ and $\mathrm{S}$ in $6 \mathrm{~N}$ pure copper were detected as the background by GDMS sputtering for a long time until stable results were obtained. Under the optimized discharge conditions above, the concentrations of $\mathrm{C}, \mathrm{N}, \mathrm{O}$ and $\mathrm{S}$ in the certified reference material (IARM Ni909-18) and the iron-nickel-based superalloy sample were detected calibrating by standard RSF. The results, listed in Table 4, show that the background of C, N, O and S was 10 to 100 times lower than that of the certified reference material and the sample. The detection of these four gas elements was effective.

Under the optimized discharge conditions above, the RSF of the 12 elements in the iron-nickel-based superalloy was obtained for 
Table 5. Comparison of Standard RSF and Calibration RSF

\begin{tabular}{llllll}
\hline Element & Std. RSF & $\begin{array}{l}\text { Calib. } \\
\text { RSF }\end{array}$ & Elements & Std. RSF & $\begin{array}{l}\text { Calib. } \\
\text { RSF }\end{array}$ \\
\hline $\mathbf{A l}$ & 1.27 & 2.01 & $\mathrm{Mn}$ & 1.01 & 1.42 \\
$\mathbf{B}$ & 6.49 & 5.02 & $\mathrm{~N}$ & 1 & 0.03 \\
$\mathbf{C}$ & 9.27 & 0.5 & $\mathrm{O}$ & 1 & 0.02 \\
$\mathbf{C r}$ & 1.28 & 2.42 & $\mathrm{P}$ & 3.66 & 8.71 \\
$\mathbf{C u}$ & 2.44 & 6.01 & $\mathrm{~S}$ & 3.43 & 4.01 \\
$\mathbf{M g}$ & 1.51 & 18.12 & $\mathrm{Ta}$ & 1.24 & 2.77 \\
\hline
\end{tabular}

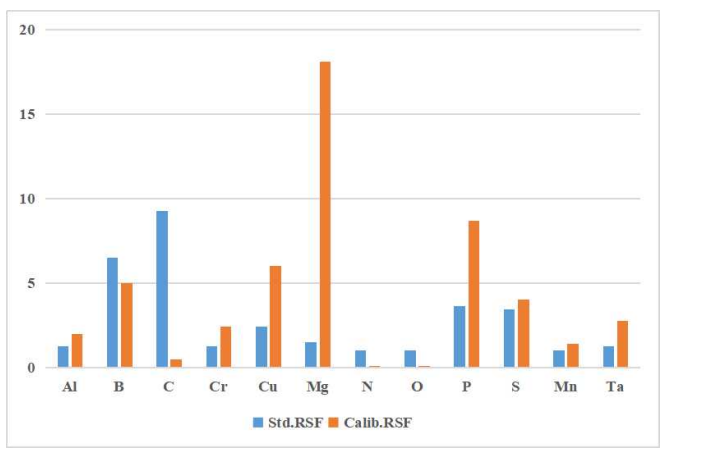

Fig. 3 Comparison of the standard RSF and the calibration RSF.

Table 6. Comparison of Measured Values and the Certified Values of the Reference Material

\begin{tabular}{lllll}
\hline Element & $\begin{array}{l}\text { Average } \\
\boldsymbol{w} /(\boldsymbol{\mu g} / \mathbf{g})\end{array}$ & $\begin{array}{l}\text { RSD } \\
(\mathbf{n}=\mathbf{4}) / \boldsymbol{\%}\end{array}$ & $\begin{array}{l}\text { Certified } \\
\boldsymbol{w} /(\boldsymbol{\mu g} / \mathbf{g})\end{array}$ & $\begin{array}{l}\text { Relative Error } \\
\boldsymbol{w} /(\boldsymbol{\mu g} / \mathbf{g})\end{array}$ \\
\hline $\mathbf{A l}$ & 92 & 0.5 & 90 & 2.25 \\
$\mathbf{B}$ & 13.2 & 1.1 & 13 & 1.84 \\
$\mathbf{C}$ & 59.8 & 0.8 & 60 & -0.3 \\
$\mathbf{C r}$ & 101.6 & 0.4 & 100 & 1.59 \\
$\mathbf{C u}$ & 69.4 & 0.8 & 70 & -0.88 \\
$\mathbf{M g}$ & 1 & 6.9 & 1.2 & -16.4 \\
$\mathbf{M n}$ & 304.3 & 0.3 & 300 & 1.42 \\
$\mathbf{N}$ & 25.5 & 1 & 26 & -1.89 \\
$\mathbf{O}$ & 40.4 & 0.8 & 40 & 1.03 \\
$\mathbf{P}$ & 20.3 & 1.3 & 20 & 1.7 \\
$\mathbf{S}$ & 17.6 & 2.3 & 18 & -2.28 \\
$\mathbf{T a}$ & 60.6 & 0.7 & 60 & 1.08 \\
\hline
\end{tabular}

Table 7. Comparison of GDMS Quantitative Analysis, Semiquantitative Analysis and Verification Test Results for 12 Elements

\begin{tabular}{|c|c|c|c|c|c|c|}
\hline Element & $\begin{array}{l}\text { Quant. } \\
w /(\mu \mathrm{g} / \mathrm{g})\end{array}$ & $\begin{array}{l}\text { RSD } \\
(n=4) \\
1 \%\end{array}$ & $\begin{array}{l}\text { Semi- } \\
\text { quant. } \\
w /(\mu \mathrm{g} / \mathrm{g})\end{array}$ & $\begin{array}{l}\text { ICP- } \\
\text { MS/OES } \\
w /(\mu \mathrm{g} / \mathrm{g})\end{array}$ & $\begin{array}{l}\mathrm{C}, \mathrm{S} \\
w /(\mu \mathrm{g} / \mathrm{g})\end{array}$ & $\begin{array}{l}O, N \\
w /(\mu \mathrm{g} / \mathrm{g})\end{array}$ \\
\hline Al & 358 & 0.8 & 235 & 327 & I & I \\
\hline B & 110 & 0.5 & 154 & 106 & I & I \\
\hline C & 160 & 0.5 & 3096 & I & 167 & I \\
\hline $\mathrm{Cr}$ & 42 & 0.8 & 22 & 45 & I & I \\
\hline $\mathrm{Cu}$ & 30 & 1.3 & 12 & 32 & I & I \\
\hline Mg & 0.52 & 12.7 & 0.046 & 0.46 & I & I \\
\hline Mn & 5587 & 0.2 & 3977 & 5182 & I & I \\
\hline $\mathbf{N}$ & 13 & 3.7 & 433 & I & I & 10 \\
\hline O & 37 & 2 & 2116 & I & I & 41 \\
\hline $\mathbf{P}$ & 13 & 0.6 & 6.1 & 11 & I & I \\
\hline $\mathbf{S}$ & 8.5 & 0.7 & 7.1 & I & 8 & I \\
\hline Ta & 14 & 1.8 & 6.1 & 13 & I & I \\
\hline
\end{tabular}

the matrix-matched certified reference material (IARM Ni909-

18). The comparison between the calibration RSF value and the standard RSF value in the instrument is shown in Table 5 and
Fig. 3. It should be noted that the calibration RSF values of $C, N$, $\mathrm{O}$ and $\mathrm{Mg}$ were obviously different from those of the standard RSF.

Under the same discharge conditions, the calibration RSF was used for four independent determinations of the reference material. The comparison between the measured values and the certified values are shown in Table 6 . The relative standard deviation (RSD) of four independent determinations was less than $7.0 \%$, and the relative error was within $\pm 16.4 \%$. These results proved that the method is stable and accurate.

Under the same discharge conditions, the standard RSF (semiquantitative) in the instrument and the calibration RSF (quantitative) were used for four independent determinations of an iron-nickel-based superalloy. The methods of ICP-OES, ICP-MS, high frequency combustion infrared absorption (for $\mathrm{C}, \mathrm{S}$ ) and inert gas pulse infrared thermal conductivity (for $\mathrm{O}, \mathrm{N}$ ) were used to verify the results of GDMS. The results of the GDMS quantitative analysis were closer to the four-verification method results than that of the semi-quantitative analysis, as shown in Table 7. However, there was no order of magnitude difference between the analysis results of semi-quantitative and quantitative analysis, except for $\mathrm{C}, \mathrm{N}, \mathrm{O}$, and $\mathrm{Mg}$. The big difference between the analysis results of semi-quantitative and quantitative for $\mathrm{N}, \mathrm{O}, \mathrm{Mg}$ was that the calibration RSF was obviously different from the standard RSF in the instrument, as discussed above. The RSD of four independent determinations was between $0.5 \% \sim 12.7 \%$, which showed good precision.

Semi-quantitative analysis for other elements. Semiquantitative determination for other elements without definite value in the iron-nickel-based superalloy reference material was carried out by using standard RSF in the instrument. The results of the GDMS semi-quantitative analysis were verified by ICP-MS, as shown in Table 8. Because the detection limit of ICP-MS was not as low as of GDMS, the results of many elements in the ICPMS analysis were only given as below detection limit. Generally speaking, there were no significant differences between the results of GDMS and ICP-MS. Some element results of GDMS and ICP$\mathrm{MS}$ are even close, such as for $\mathrm{Sb}$.

\section{CONCLUSIONS}

A high-resolution glow discharge mass spectrometric method for the quantitative and semi-quantitative analysis of trace elements in iron-nickel-based superalloy was successfully developed. The method involves use of a matrix-matched certified reference material, IARM Ni909-18. Quantitative analysis was carried out by using the calibration RSFs, which were obtained from 12 elements in the certified reference material. A comparison of the results obtained with GDMS, ICP-OES, ICP-MS, high frequency combustion infrared absorption and inert gas pulse infrared thermal conductivity shows good agreement between the methods. Semi-quantitative analysis was carried out by using standard RSF 
Table 8. Comparison of GDMS Semi-quantitative Analysis and ICPMS Verification Test Results for Additional 52 Elements

\begin{tabular}{|c|c|c|c|c|c|}
\hline Element & $\begin{array}{l}\text { Semi- } \\
\text { quant. } \\
w /(\mu \mathrm{g} / \mathrm{g})\end{array}$ & $\begin{array}{l}\text { ICP- } \\
\mathrm{MS} \\
w /(\mu \mathrm{g} / \mathrm{g})\end{array}$ & Element & $\begin{array}{l}\text { Semi- } \\
\text { quant. } \\
w /(\mu \mathrm{g} / \mathrm{g})\end{array}$ & $\begin{array}{l}\text { ICP- } \\
\text { MS } \\
w /(\mu \mathrm{g} / \mathrm{g})\end{array}$ \\
\hline $\mathbf{L i}$ & $<0.05$ & $<1$ & Cs & $<0.05$ & $<0.5$ \\
\hline Be & $<0.05$ & $<0.5$ & $\mathbf{B a}$ & $<0.05$ & $<0.5$ \\
\hline $\mathrm{Na}$ & 0.12 & $<3$ & La & $<0.05$ & $<0.5$ \\
\hline $\mathbf{K}$ & 0.2 & $<5$ & $\mathrm{Ce}$ & $<0.05$ & $<0.5$ \\
\hline Ca & $<0.05$ & $<1$ & Pr & $<0.05$ & $<0.5$ \\
\hline Sc & $<0.05$ & $<1$ & Nd & $<0.05$ & $<0.5$ \\
\hline V & 0.83 & $<1$ & Sm & $<0.05$ & $<0.5$ \\
\hline $\mathbf{Z n}$ & 0.17 & $<1$ & Eu & $<0.05$ & $<0.5$ \\
\hline Ga & 7.35 & 6.3 & Gd & $<0.05$ & $<0.5$ \\
\hline Ge & 2.13 & 7.8 & $\mathbf{T b}$ & $<0.05$ & $<0.5$ \\
\hline As & 8.64 & 11 & Dy & $<0.05$ & $<0.5$ \\
\hline Se & 1.78 & 1.6 & Ho & $<0.05$ & $<0.5$ \\
\hline $\mathbf{R b}$ & $<0.05$ & $<0.5$ & $\mathbf{E r}$ & $<0.05$ & $<0.5$ \\
\hline $\mathrm{Sr}$ & $<0.5$ & $<0.5$ & Tm & $<0.05$ & $<0.5$ \\
\hline $\mathbf{Y}$ & $<0.5$ & $<0.5$ & $\mathbf{Y b}$ & $<0.05$ & $<0.5$ \\
\hline $\mathbf{Z r}$ & 0.5 & 0.77 & Lu & $<0.05$ & $<0.5$ \\
\hline Mo & 2.29 & 3.4 & Hf & $<0.05$ & $<0.5$ \\
\hline $\mathbf{R u}$ & $<0.05$ & $<0.5$ & $\mathbf{W}$ & 1.31 & 5 \\
\hline $\mathbf{R h}$ & $<0.05$ & $<0.5$ & $\mathbf{R e}$ & $<0.05$ & $<0.5$ \\
\hline Pd & $<0.05$ & $<0.5$ & $\mathbf{I r}$ & $<0.05$ & $<0.5$ \\
\hline Ag & 4.72 & 1.8 & $\mathbf{P t}$ & $<0.05$ & $<0.5$ \\
\hline Cd & 0.36 & $<0.5$ & Au & $<0.05$ & $<0.5$ \\
\hline In & $<0.05$ & $<0.5$ & $\mathrm{Hg}$ & $<0.05$ & $<1$ \\
\hline Sn & 5.11 & 9.1 & Tl & $<0.05$ & $<0.5$ \\
\hline Sb & 1.99 & 2 & $\mathbf{P b}$ & $<0.05$ & $<0.5$ \\
\hline Te & $<0.05$ & $<0.5$ & $\mathbf{B i}$ & $<0.05$ & $<1$ \\
\hline
\end{tabular}

in the instrument. No significant differences between the results of GDMS and ICP-MS were found. The validation reveals that the proposed approach achieves reliable results for the rapid determination of several impurities, such as metals as well as nonmetals, and even for the gas elements of $\mathrm{C}, \mathrm{N}, \mathrm{O}$ and $\mathrm{S}$.

\section{AUTHOR INFORMATION}

\section{Corresponding Author}

*C. H. Wang.

Email address: wangchanghua@gbtcgroup.com

Notes

The authors declare no competing financial interest.

\section{REFERENCES}

1. G. L. Chen, Superalloys. Beijing, Metallurgical Industry Press, 1988.

2. R. C. Reed, The superalloys: Fundamentals and applications. Cambridge Univ. Press, 2008.

3. Y. T. Chen, Y. J. Chang, H. Murakami, S. Gorsse, and A. H. Yeh, Scr. Mater., 2020, 187, 177-182. https://doi.org/10.1016/j.scriptamat.2020.06.002

4. Z. C. Xu and P. L. Ma, Effect and control of trace elements in superalloys. Beijing, Metallurgical Industry Press, 1987.

5. ASTM E1473-16, Standard test methods for chemical analysis of nickel, cobalt, and high-temperature alloys.

6. ASTM E2594-14, Standard test method for analysis of nickel alloys by inductively coupled plasma atomic emission spectrometry.

7. ASTM E 1834-11, Standard test method for analysis of nickel alloys by graphite furnace atomic absorption spectrometry.

8. ASTM E2823-11, Standard test method for analysis of nickel alloys by inductively coupled plasma mass spectrometry.

9. ISO 9388:2009, Nickel alloys - determination of phosphorus content - molybdenum blue molecular absorption spectrometric method.

10. ISO 11437-2:2010, Nickel alloys - determination of trace element content by electrothermal atomic absorption spectrometric method part 2: determination of lead content.

11. ISO 22725:2011, Nickel alloys - determination of tantalum - inductively coupled plasma atomic emission spectrometric method.

12. HB 5220. National Defense Science, Technology and Industry Commission of P. R. China. 2008.

13. GJB 8781. Commission of Science, Technology and Industry for National Defence of the P. R. China. 2015

14. GB/T 20127. National Standardization Administration of P. R. China. 2006.

15. GB/T 223. National Standardization Administration of P. R. China. 2019.

16. T. Lv and Y. Guo, Chin. J. Inorg. Anal. Chem., 2020, 10(2), 11-14. https://doi.org/10.3969/j.issn.2095-1035.2020.02.003

17. F. Luo, Chin. J. Inorg. Anal. Chem., 2020, 10(4), 59-62. https://doi.org/10.3969/j.issn.2095-1035.2020.04.013

18. S. M. Mo, A. C. Li, X. Zhang, C. D. Qiu, C. B. Dong, and L. H. Zhu, Chem. Anal. Meter, 2020, 29(3), 129-132. https://doi.org/10.3969/j.issn.1008-6145.2020.03.028

19. G. W. Yang, Y. X. Hou, Q. B. Liu, and X. J. Li, Metall. Anal., 2019, 39(4), 1-6. https://doi.org/10.13228/j.boyuan.issn1000-7571.010600

20. D. Na, Y. Sun, M. Wang, and H. Li, Chin. J. Inorg. Anal. Chem., 2019, 9(6), 54-58. https://doi.org/10.3969/j.issn.2095-1035.2019.06.012

21. X. Yu, X. J. Li, and H. Z. Wang, Metall. Anal., 2011, 31(11), 1-6. https://doi.org/10.13228/j.issn.1000-757.2011.11.004

22. X. Yu, X. J. Li, H. Z. Wang, Metall. Anal., 2007, 27(4), 11-17. https://doi.org/10.13228/j.issn.1000-757.2007.04.002

23. K. Su, X. W. Wang, and K. Putyera, Metall. Anal., 2011, 31(11), 18-23. https://doi.org/10.13228/j.issn.1000-757.2011.11.006

24. C. D.Quarles Jr, J. Castro, and R. K. Marcus, Encyclopedia of Spectroscopy and Spectrometry (Third Edition), 2017, p30-36 https://doi.org/10.1016/B978-0-12-374413-5.00056-7

25. W. Vieth and J. C. Huneke, Anal. Chem., 1992, 64, 2958-2964. https://doi.org/10.1021/ac00047a014

26. S. Raparthi, J. Arunachalam, N. Das, and A. M. S. Murthy, Talanta, 2005, 65, 1270-1278. https://doi.org/10.1016/j.talanta.2004.09.001

27. R. Shekhar, M. A. Reddy, S. Thangavel, Y. Sunitha, A. C. Sahayam, and S. Kumar, At. Spectrosc., 2020, 41(3), 103-109. https://doi.org/10.46770/AS.2020.03.002

28. M. D. Sabatino, A. L. Dons, J. Hinrichs, and L. Arnberg, Spectrochim. Acta B, 2011, 66, 144-148. https://doi.org/10.1016/j.sab.2011.01.004

29. G. Chen, A. J. Ge, S. J. Zhuo, and P. L. Wang, 
J. Chin. Mass Spectro. Soc., 2007, 28(1), 36-39. https://doi.org/10.3969/j.issn.1004-2997.2007.01.008

30. Y. X. Hou, X. B. Liu, G. W. Yang, X. J. Li, and J. Y. Hu, PTCA (Part B: Chem. Anal.), 2020, 56(3), 315-319. https://doi.org/10.11973/lhjy-hx202003011

31. M. D. Sabatino, Measurement, 2014, 50, 135-140. https://doi.org/10.1016/j.measurement.2013.12.024

32. C. Modanese, L. Arnberg, and M. D. Sabatino, Mater. Sci. Eng. B, 2014, 180, 27-32.

https://doi.org/10.1016/j.mseb.2013.10.010

33. X. Yu, X. J. Li, and H. Z. Wang, PTCA (Part B: Chem. Anal.), 2010, 46(2), 206-210. https://doi.org/CNKI:SUN:LHJH.0.2010-02-041

34. B. L. Rong, Y. Zhen, L. B. Tang, and R. B. Ji,
J. Chin. Mass Spectrom. Soc., 2006, 27(Supplement), 25-26.

35. X. Yu, X. J. Li, and H. Z. Wang, Int J Mass Spectrom, 2007, 262, 25-32. https://doi.org/10.1016/j.ijms.2006.10.001

36. X. J. Wei, Z. Qin, P. H. Xiong, L. P. Wang, H. L. Zhang, D. C. Deng, and J. S. Liao, Spectrochim. Acta B, 2019, 154, 43-49. https://doi.org/10.1016/j.sab.2019.01.004

37. A. Bogaerts, K. A. Temelkov, N. K. Vuchkov, and R. Gijbels, Spectrochim. Acta B, 2007, 62, 325-336. https://doi.org/10.1016/j.sab.2007.03.010

38. K. Wagatsuma, T. Saka, M. Yamaguchi, and K. Ito, J. Anal. Atom. Spectrom., 2002, 17(10), 1359-1362. https://doi.org/10.1039/b204747k 